\title{
ČEZMEJNO IZOBRAŽEVANJE IN TVEGANJA ZA NACIONALNO VARNOST
}

Povzetek Prispevek predstavlja kritično razmišljanje o internacionalizaciji visokega šolstva oziroma o njenem najbolj hitro naraščajočem in razvijajočem delu - čezmejnem izobraževanju in pregledu nad tveganji, ki so povezana $\mathrm{z}$ omenjenim pojavom $\mathrm{v}$ kontekstu vpliva na nacionalno varnost. Uporabili smo deskriptivno metodo, zlasti pri konceptualizaciji ključnih pojmov, in analizo vsebine primarnih in sekundarnih virov, pri čemer smo podatke dobili iz domače in tuje strokovne literature, internetnih virov in pravnih dokumentov. Nacionalne vladne politike pomembno vplivajo na proces in izide čezmejnega izobraževanja, zato je za strateško delovanje in napoved trendov bistven pregled nad trenutnim stanjem in morebitnimi tveganji (neokolonializem, beg možganov in korupcija). Ugotavljamo, da je z vidika zagotavljanja gospodarske konkurenčnosti in posledično nacionalne varnosti posameznih držav nujno potrebna identifikacija trenutnega stanja in analiza pomena trendov na področju čezmejnega izobraževanja.

Ključne Čezmejno izobraževanje, nacionalna varnost, neokolonializem, globalizacija, besede korupcija in beg možganov.

Abstract The paper provides a critical reflection on the internationalization of higher education, more specifically of its most rapidly growing and evolving part - cross border education, as well as presents an overview of the risks associated with the above phenomenon in the context of the impact on national security. For the purposes of the paper we have used the descriptive method, especially in conceptualizing key points, and analysis of the primary and secondary sources content was done, where the data was drawn from the domestic and foreign literature, internet resources, and legal documents. National government policies have a significant impact on the process and outcomes of the cross-border education. Strategic performance and trend forecast are thus essential for an overview of the current situation and potential risks (neo-colonialism, brain drain and corruption). We have found that in terms of 
ensuring the economic competitiveness and, consequently, the national security of individual countries an identification of the current state and the analysis of trend importance in cross border education is needed.

\section{Keywords Cross-border education, national security, neo-colonialism, globalization, corrup- tion and brain drain.}

Uvod Neizogibni ekonomski, tehnološki, politični, kulturni in znanstveni trendi, ki jih prinaša globalizacija, neposredno vplivajo na pospešeno internacionalizacijo visokega šolstva (Altbach, 2005, str. 64). Ta obsega sistematična in stalna prizadevanja, da bi zagotovili visoko šolstvo (bolj) odzivno na zahteve in izzive globalizacije in tako vključuje različne politike in programe, sprejete na nadnacionalnih, nacionalnih in organizacijskih ravneh. »Internacionalizacijo v visokem šolstvu lahko označimo kot zelo normativno temo z močnimi političnimi tokovi« (Kehm in Teichler, 2007, str. 262). V evropskem visokem šolstvu je zelo pozitivno razumljena, in sicer kot fenomen z obsežnim naborom dejavnosti, ki ima zelo pomembno vlogo, saj pospešuje gospodarsko rast in družbeno blaginjo nacionalnih držav in posledično Evropske unije kot celote.

Internacionalizacija visokega šolstva doživlja razcvet od leta 1990 dalje, v zadnjih desetih letih pa ugotavljamo zelo veliko povečanje njenega najbolj hitro razvijajočega dela - čezmejno izobraževanje. Nastajajoče nove oblike čezmejnih dejavnosti, novi »igralci« iz zasebnega sektorja ter dejstvo, da je čezmejno izobraževanje postalo milijarde dolarjev vredna industrija, in pomanjkanje podatkov o stanju na globalnem trgu visokega šolstva - vse to sproža vprašanje o morebitnih tveganjih. Pozitivni izidi čezmejnega izobraževanja se lahko izrodijo $\mathrm{v}$ negativne posledice, zlasti $\mathrm{v}$ odvisnost od tujih ponudnikov izobraževanja, beg možganov, korupcijo, povečanje števila tujih (nepoštenih) ponudnikov in slabe kakovosti storitev, problem tujih kvalifikacij itn. Namen našega prispevka je kritično predstaviti pospešeno čezmejno izobraževanje in tveganja, povezana s tem fenomenom. Kritični pogled je vsekakor relevanten, saj se visokošolsko okolje v zadnjih desetletjih močno spreminja, tudi z vidika vloge, ki jo nova paradigma družbe znanja podeljuje visokemu šolstvu: »usmerjenost $\mathrm{v}$ doseganje skupnega dobrega, konkurenčnost naroda in družbe $\mathrm{v}$ globalnem svetu« (Nokkala, 2006, str. 177). Pripisana vseobsegajoča dimenzija sega tako od gospodarske rasti, izobraževanja, pridobivanja človeškega kapitala itn. do posledičnega vpliva h krepitvi nacionalne varnosti. Nacionalne vladne politike imajo pomemben vpliv na izide čezmejnega izobraževanja, zlasti na nabor namenov, dejavnosti, sodelovanja in pravnih mehanizmov. Za strateško delovanje in napoved trendov pa je bistveno imeti pregled nad trenutnim stanjem in morebitnimi tveganji. 


\section{1 ČEZMEJNO IZOBRAŽEVANJE IN GLOBALNI TRG VISOKEGA ŠOLSTVA}

Globalizacija je proces, ki vpliva na dojemanje sveta kot majhne globalne vasi in na dejstvo, da »notranja politična vprašanja postajajo vse bolj eksternalizirana in zunanja politična vprašanja vse bolj internalizirana. Tradicionalno domače politike, kot sta zdravstvo, človekove pravice itn. tako postajajo vse vidnejše na svetovnem političnem prizorišču. (Hough, 2004, str. 2). Vedno pomembnejša tema je tudi visokošolsko izobraževanje, saj je znanje bistveno za državo in njen gospodarski razvoj. Evropska unija z Lizbonsko strategijo in ciljem »postati najbolj konkurenčno in dinamično na znanju temelječe gospodarstvo na svetu, sposobno trajnostne gospodarske rasti $\mathrm{z}$ več in boljšimi delovnimi mesti ter večjo socialno kohezijo« (Commission of the European Communities [COM], 2003, str. 2) odpre diskurz o družbi znanja ${ }^{1}$ (Valimaa in Hoffman, 2008, str. 275) in pri njenem ustvarjanju visokošolskim sistemom in posameznim visokošolskim organizacijam podeli pomembno vlogo. Teorija o družbi znanja ${ }^{2}$, po kateri je znanje glavni vir prihodka razvitih gospodarstev, je tako spodbudila prepričanje, da lahko države z vlaganjem v visoko šolstvo dosežejo mednarodno konkurenčnost (Scott, 1998, str. 110 v Chan, 2004, str. 34). V tem kontekstu je poglavitna internacionalizacija visokega šolstva, sicer težko govorimo o visokošolskih sistemih in organizacijah kot o ustvarjalcih na znanju temelječe družbe in gospodarstva, saj so ti »sestavni del stalnega pretoka ljudi, znanja, informacij, tehnologij, proizvodov in finančnega kapitala« (Marginson, 2006 v Valimaa in Hoffman, 2008, str. 266).

Najbolj razširjena definicija internacionalizacijo ${ }^{3}$ opredeljuje $»$ na nacionalnem, sektorskem in institucionalnem nivoju kot proces integracije mednarodnih, medkulturnih ali globalnih razsežnosti v cilje, dejavnosti visokošolskih institucij« (Knight, 2005, str. 13). Čezmejno izobraževanje (angl. crossborder eduaction) predstavlja podmnožico internacionalizacije oziroma en del internacionalizacije ${ }^{4}$, ki zajema "pretok ljudi, programov, izvajalcev, znanja, idej, projektov, vrednot, kurikulov in storitev prek državnih meja« (Knight, 2008, str. 98; Knight, 2011, str. 19). Tako se internacionalizacija nanaša na koncept »procesa«, ki v primerjavi s čezmejnim

\footnotetext{
Izraz družba znanja se na ravni Evropske unije uporablja $v$ dveh različnih, vendar povezanih pomenih. V prvem se družba znanja uporablja kot opisni pojem in se sklicuje na nove dinamike industrijske rasti in družbenih sprememb, ki so bile vidne v zadnjih desetletjih. Drugič pa se pojmuje kot izraz za namero ustvariti družbo znanja, kar je povezano z gospodarsko rastjo, večjo blaginjo, boljšo kakovostjo delovnih mest itn. (European Foundation for the Improvement of Living and Working Conditions, 2005, str. 1).

2 Znanje, njegova produkcija in prenos, je prepoznano kot gonilo gospodarskega in družbenega napredka, visokošolski sistemi in organizacije pa kot »ključ« do družbe znanja in na znanju temelječega gospodarstva (COM, 2003, str. 58).

3 Internacionalizacija predvsem v razvitih industrijskih državah postaja vidnejše tematsko področje visokega šolstva in doživi velik trend okoli leta 1990 (Kehm in Teichler, 2007, str. 261). Sicer ne predstavlja novega fenomena, saj so študenti in profesorji prehajali državne meje že v preteklosti, se pa v zadnjih dvajsetih letih močno spremeni v smeri trenda vse večjega izobraževanja prek državnih mej (Knight, 2008, str. 95).

4 Drugo podmnožico internacionalizacije označimo kot internacionalizacija doma oziroma internacionalizacija, zasnovana na kampusu (angl. internationalization at home or campus-based) in se nanaša na aktivnosti $v$ sklopih, a) kurikul in programi, b) proces učenja, c) obštudijske dejavnosti, d) povezave z lokalnimi kulturnimi oziroma etničnimi skupinami in e) raziskovalne in znanstvene aktivnosti.
} 
izobraževanjem razširi pomen nad dejavnosti in se navezuje na internacionalno razsežnost vseh vidikov visokošolskega izobraževanja (Knight, 2005, str. 13).

Smo v dobi čezmejnega izobraževanja, ki prinaša vse večje število novih vrst ponudnikov, novih načinov dostave, novih programov, kvalifikacij itn., kar spreminja naravo in obliko sodelovanja med državami, visokošolskimi sistemi in organizacijami (Knight, 2008; Knigt, 2011). Ponudbo storitev čezmejnega izobraževanja je leta 1998 zaznal tudi sekretariat WTO (angl. World Trade Oganization) in predlagal njeno ureditev znotraj WTO kot poslovno storitev. Leta 1999 je bil predlog sprejet, s čimer je izobraževanje postalo vključeno v pogajanja o novih storitvah januarja 2000 (Tilak, 2011, str. 33). Z novim sporazumom o mednarodni trgovini GATS (angl. General Agreement of Trade in Services) je visokošolsko izobraževanje postalo tržno blago oziroma storitev ${ }^{5}$, s katero se mednarodno trguje, izobraževanje pa je kategorizirano na enak način kot sektorji transport, komunikacije, zdravstvo in kultura (Knigt, 2011, str. 20-38). Izobraževanje je postalo tržno blago, kar ima precejšen vpliv na povečanje čezmejnih dejavnosti in na globalni trg visokega šolstva.

\section{2 ČEZMEJNO IZOBRAŽEVANJE IN NACIONALNA VARNOST}

Globalizacija je vplivala (in še vedno vpliva) na preoblikovanje čezmejnega izobraževanja (Knight 2008, 1) in na spremembo varnostne paradigme ${ }^{6} \mathrm{v}$ kontekstu novega kompleksnega (globalnega) varnostnega okolja in vlogo države pri zagotavljanju sodobne varnosti ${ }^{7}$ (Grizold in Bučar, 2011, str. 827). V globalizacijskem procesu ${ }^{8}$ so države postale bolj soodvisne, v odnose vstopajo novi nedržavni subjekti (multinacionalna podjetja, nevladne organizacije itn.) in narašča število nevojaških groženj (Grizold in Bučar, 2011, str. 830). Nove nevarnosti in izzivi, ki jih procesi prinašajo tako na ravni posameznika, družbe in sodobne države, so postopoma privedli do celovitejše obravnave nacionalne varnosti (Sotlar, 1994, str. 93).

\footnotetext{
Storitve so definirane na štiri načine: a) čezmejno zagotavljanje storitev, pri čemer se potrošniki fizično ne premikajo oziroma ostanejo v lastni državi. Sklop opredeljuje mobilnost storitev, kot na primer izobraževanje na daljavo in e-učenje; b) poraba v tujini, kjer potrošniki prehajajo čez meje v druge države. Opredeljena je mobilnost potrošnikov oziroma uporabnikov storitev, ki del izobraževanja ali celotno izobraževanje opravijo $v$ drugi državi; c) prisotnost ponudnika $v$ drugi državi (institucionalna mobilnost); d) prisotnost osebja v drugi državi (mobilnost zaposlenih) (Tilak, 2011, str. 17; Knight, 2008, str. 88; Knight, 2011, str. 20).

${ }^{6}$ Kot pravita Grizold in Bučar (2011, str. 830-831) se omenjena razsežnost izkazuje v dveh smereh: a) ozemeljski, ki vključuje posameznike, skupine in organizacije na lokalni, državni, regionalni in svetovni ravni in b) konceptualni, ki vključuje vse vidike človekovega obstoja in delovanja (kulturnega, ekonomskega, političnega, izobraževalnega, zdravstvenega, obrambnega idr.).

Glede pojasnjevanja vloge države in varnosti v dobi globalizacije in »novih « odnosov med državami (in tudi novimi akterji), glede vidika razjasnitve perspektive odnosov med nacionalnim gospodarstvom in nacionalno varnostjo $v$ sodobnih državah in glede vidika razjasnitve praktičnih vprašanj o varnosti v sodobnih družbah se lahko opremo na (Malešič 1994) tri sodobne perspektive: a) politika moči in varnosti-temelji na realizmu in poudarja kvazianarično naravo mednarodnega sistema in posledično ukvarjanje nacionalnih držav z varnostjo; b) politika soodvisnosti in transnacionalnih odnosov - temelji na liberalizmu in poudarja sožitje in interakcijo množice politično aktivnih skupin v svetovnem sistemu; c) politika nadvlade in odvisnosti - temelji na marksizmu in se ukvarja za vprašanjem, kako lahko revne in šibke države eksistirajo v globalnem sistemu.

${ }^{8}$ Kot pravi Svete (2005, str. 81), se globalizacija nanaša na tri fenomene: a) številne politične, ekonomske in družbene dejavnosti postajajo medregionalne oziroma celo medkontinentalne, b) bistveno povečana stopnja interakcije med državami, c) relativizacija pomena držav v primerjavi z drugimi političnimi akterji na mednarodnem, nadnacionalnem in transnacionalnem prizorišču.
} 
Nacionalno varnost opredelimo kot »varnost državnega naroda, ki vključuje varnost nacionalnega ozemlja (vključno z zračnim prostorom in teritorialnimi vodami), zaščito in varovanje življenja ljudi in njihove lastnine, ohranitev in vzdrževanje nacionalne suverenosti ter uresničevanje temeljnih funkcij družbe« (Grizold, 1992, str. 65 v Sotlar, 2001, str. 192). Varnost svojih državljanov država zagotavlja z zagotavljanjem notranjega reda in miru ter obrambo pred napadi od zunaj in z reguliranjem zagotavljanja socialno-gospodarskih, političnih, izobraževalnih in drugih funkcij družbe (Grizold, 2005, str. 26). Nacionalnovarnostna politika tako predstavlja načrt zagotavljanja celostne varnosti na ravni družbe, države in posledično tudi posameznika (Sotlar, 2001, str. 190). V vsebinskem smislu danes vključuje vse vidike človekovega obstoja in delovanja $\mathrm{v}$ družbi ter tudi vse ravni družbenega povezovanja (Grizold, 2005, str. 26-23). Za uresničevanje oziroma zagotavljanje omenjenega mora nacionalna varnostna politika predstavljati oziroma obsegati skupek različnih sektorskih politik (zunanje, obrambne, gospodarske, ekološke, socialne, zdravstvene, kriminalitetne, izobraževalne itn.), ki prek vzpostavitve in delovanja varnostnih mehanizmov in instrumentov vsaka izmed njih v svojem delu prispeva k zagotavljanju nacionalne varnosti (Sotlar, 2001, str. 191). V Resoluciji o strategiji nacionalne varnosti RS (2010) je zapisano, da »se v skladu s sodobnim večdimenzionalnim razumevanjem pojma nacionalne varnosti upošteva tudi varnostni vidik politike države na gospodarskem, socialnem, okoljskem, zdravstvenem, demografskem, izobraževalnem, znanstveno-tehnološkem, informacijskem in drugih področjih«.

Iz tradicionalnih dejavnosti (poučevanje in raziskovanje) in nove vloge (skrb za gospodarski razvoj) visokega šolstva je razvidno, da s svojim delovanjem veliko prispeva pri razvoju blaginje države in posredno tudi pri zagotavljanju nacionalne varnosti. Prek svoje gospodarske, raziskovalne in izobraževalne vloge prispeva $\mathrm{k}$ zagotavljanju naše varnosti ter kakovosti življenja in prek javne razprave omogoča gospodarsko in politično stabilnost naroda. To pa je pomembno z vidika učinkovitega zagotavljanja nacionalne varnosti, saj je pri oblikovanju varnostne politike države treba upoštevati tudi mnenja, stališča, prepričanja in vrednote državljank in državljanov o poslanstvu politične države in nacionalnovarnostnega sistema (Obramboslovni raziskovalni center, 2003, str. 3). Politični nameni za spodbujanje čezmejnega delovanja so tako povezani predvsem z vprašanji državne varnosti, stabilnosti in miru (Kreber, 2009, str. 3).

Čezmejno delovanje visokega šolstva je za državo bistveno, saj omogoča razvoj človeških virov, mednarodnih strateških povezav, znanstveno-tehnološki in gospodarski razvoj (Knight, 2005, str. 17-19) in je koristno tako za gospodarstvo države, ki izobraževanje »izvaža«, kot tudi za prejemnice. Temeljne koristi so predvsem (Centre for International Economics, 2008, str. 23): prenos idej in možnosti izobraževanja, povečanje virov, dostopnih za izobraževanje - povečanje števila storitev izobraževanja, izboljšanje kakovosti, pridobivanje novih zvez, sodelovanja, mrež in kulturno razumevanje. Pri tem dostopamo do novih informacij, diskusij in težav, s katerimi se spoprijema svet, kar omogoča pozitivne spremembe pri sodelovanju, ozaveščanju in izobraževanju o različnih problemih, kot so globalne teroristične 
mreže, okoljska politika, trgovina z ljudmi, trgovina z mamili, neformalna ekonomija itn. »Učinkoviti izobraževalni sistemi so torej ključnega pomena pri zagotavljanju trajnega miru in razvoja« (Al-Rodhan, 2007, str. 13).

Menimo, da hitro spreminjajoča se čezmejna narava in liberalizacija trgovine visokošolskega izobraževanja predstavlja nove priložnosti, potenciale in tudi tveganja (Knight, 2008, str. 149). Tveganja9 ${ }^{9}$ so pomembna, saj nastajajo vedno nove oblike čezmejnih dejavnosti, kot so podružnice kampusov v tujini, programi učenja na daljavo oziroma e-učenje, mednarodna izobraževalna vozlišča in omrežja itn.; v ta proces vstopajo novi »igralci« iz zasebnega sektorja; čezmejno izobraževanje je postalo milijarde dolarjev vredna industrija in $\mathrm{v}$ mnogih državah hitro narašča; pomanjkanje podatkov o čezmejnem izobraževanju na globalnem trgu visokega šolstva. Kot pravi Prezelj (2002, str. 136) »v sodobni družbi bi bilo zelo težko kaj pridobiti in doseči brez neke stopnje tveganja, zato sistemi (posamezniki, družbe, države itn.) težijo k temu, da se ne izogibajo tveganjem, iz katerih lahko marsikaj koristnega pridobijo«. V nadaljevanju predstavljamo tveganja, ki lahko nastanejo kot posledica pospešene rasti čezmejnega izobraževanja in se nam zdijo še posebej relevantna z vidika zagotavljanja nacionalne varnosti. Gre predvsem za novi neokolonializem, beg možganov in korupcijo.

\subsection{Neokolonializem}

Neokolonializem lahko v najširšem smislu razumemo kot vmešavanje razvitih držav v države v razvoju, pri čemer se tuji kapital uporabi za izkoriščanje in ne za nadaljnji razvoj teh držav, s čimer se še povečuje prepad med bogatimi in revnimi (Nkrumah, 1965). Razvite države torej pod pretvezo ponujajo »gospodarsko« pomoč revnim državam sveta, posledice pa so neuravnotežena gospodarska razmerja, ki imajo mednarodne politične implikacije (Kelleher in Klein, 1999, str. 88). Vendar zakaj sploh govoriti o neokolonializmu?

GATS je odprl vrata pospešenemu oblikovanju globalnega trga v visokem šolstvu, kjer posamezni nacionalni visokošolski sistemi in posamezne visokošolske organizacije tekmujejo med seboj, vendar v izrazito neenakem položaju (Altbach, 2002). Nekateri avtorji (Albach, 2005; Teichler, 2009; Jiang, 2008) tako opozarjajo, da smo priča dobi novih razmerij oziroma neokolonializmu. Altbach (2005, str. 65-66), ki neokolonializem pojmuje $\mathrm{v}$ okviru razmerja odvisnosti na relaciji center - obrobje in temelji na neenakosti, saj države $\mathrm{v}$ centru želijo vpliv in moč nad državami $\mathrm{v}$ razvoju, pri tem opozarja na novo vrsto oziroma kot sam poimenuje »nov« neokolonializem. Pri tem gre za nekakšno novo dobo moči in vpliva, kjer kot neokolonialisti nastopajo tudi multinacionalne korporacije, medijski konglomerati in nekaj večjih univerz, ki v izobraževanju vidijo vir finančnih koristi. Aaltbach (2002, str. 4) pravi, da smo vstopili v povsem novo obdobje moči in vpliva, ki ga ne poganja moč politike ali ideologija, temveč dominacijo omogoča znanje oziroma prodaja znanja.

Z izrazom tveganje razumemo verjetnost nevarnosti, ki mu je subjekt izpostavljen, nevarnost pa kot dogodek oziroma izid, za katerega obstaja določena (empirična ali teoretična) verjetnost, da se bo pripetil (Prezelj, 2002, str. 134). 
Znanje se prodaja v različnih oblikah, kot so študijski programi, kampusi, skupne diplome, tuji certifikati, potrdila iz tujine, franšize, poslovni programi usposabljanja itn. Novi neokolonializem vodi dobiček in ne politika.

Države z močnimi izobraževalnimi sistemi, z univerzami z močno tradicijo in velikim ugledom prodajajo izobraževanje v tujini, običajno državam v razvoju. Te navadno vedno prevladujejo pri produkciji in distribuciji znanja, vključno z raziskavami in poučevanjem, razširjanjem znanja in novimi organizacijskimi vzorci in smernicami. Šibkejše institucije in visokošolski sistemi z manj sredstvi in nižjimi akademskimi standardi pa jim večinoma poskušajo le slediti. Večina akademskih središč ima tako veliko koristi od široke palete virov, ki jim jih zagotavljajo velike bogate države (Altbach, 2005, str. 65-66). Rezultat tega je odvisnost akademskih sistemov in institucij držav v razvoju od bogatih in močnih tujih ponudnikov (Aaltbach, 2002, str. 4). Podobno ugotavlja tudi Marginson (2004, str. 218), ki pravi, da med visokošolskim izobraževanjem razvitih držav in držav v razvoju obstajajo neenakost, dominantnost in podrejenost, vendar pri tem opozarja, da se vprašanje neenakosti ne nanaša le na države v razvoju, temveč tudi na vse druge (na primer z manjšimi visokošolskimi sistemi), ki na globalnem trgu veliko težje tekmujejo za vire, ki jih potrebujejo za delovanje. Države z močnimi in dobro razvitimi visokošolskimi sistemi in predvsem z uglednimi univerzami imajo tako prednost pri razvijanju internacionalnih dejavnosti in s tem tudi pri pridobivanju temeljnih resursov - študentov in denarja.

Države, kot so ZDA, Avstralija in Velika Britanija so s svojimi močnimi izobraževalnimi sistemi in visokošolskimi institucijami pri izvozu čezmejnega izobraževanja postale svetovni akterji. »Nakupnice« izobraževanja pa so večinoma Azija, Latinska Amerika in druge države v razvoju, s čimer želijo zapolniti vrzel naraščajočega povpraševanja po visokošolskem izobraževanju (Altbach in Knight, 2007, str. 294). Knightova (2008, str. 118) pri tem ugotavlja, da so v zadnjih petih do desetih letih postale najbolj priljubljene lokacije držav izvoznic prav Malezija, Singapur, Kitajska, Tajska in Indija. O dejstvih, številkah in primerjavah ponudbe in povpraševanja zelo težko razpravljamo, saj države večinoma ne zbirajo podatkov o izvozu in uvozu izobraževanja oziroma jih ne zbirajo na sistematičen način, s čimer sta onemogočena primerjava in pregled (Knigh, 2008). Burges in Berquist (2012, str. 326-327) na primer ugotavljata:

ZDA - približno 50 ameriških terciarnih ustanov (le 1 odstotek) ponuja več kot 200 čezmejnih programov, ki obsegajo različne oblike, vse od franšiz do kampusov. Programe izvajajo v kar 40 državah, med katerimi prevladujejo Kitajska, Južna Koreja, Vietnam, bližnji vzhod in Turčija.

Velika Britanija - 196.640 študentov je študiralo v več kot 1000 različnih čezmejnih programih v obdobju 2007-2008. Približno 65 odstotkov od 145 registriranih visokošolskih institucij ponuja čezmejne programe, 60 odstotkov teh dejavnosti pa je usmerjenih v Azijo. V letih 2006 in 2007 je 20 visokošolskih institucij ponujalo diplomsko izobraževanje (angl. degree course) prek indijskih partnerskih organizacij 
približno 4100 indijskim študentom. V Hong Kongu 81 visokošolskih institucij ponuja skupaj 617 študijskih programov.

Avstralija - leta 2010 je 104.678 študentov študiralo v avstralskih čezmejnih programih, ki jih ponujajo največ v Singapurju, Kitajski, Maleziji, Hong Kongu in Vietnamu.

Kljub razdrobljenim in bolj ali manj neprimerljivim podatkom lahko opazimo, da se na visokošolskem globalnem trgu »države v razvoju soočajo z izzivi čezmejnega izobraževanja, saj omenjeni položaj tako krepi moč predvsem v razvitih zahodnih državah, kar odpira možnost neokolonializmu« (Jiang, 2008, str. 352). Države v razvoju se na globalnem trgu srečujejo z dvema pojavoma, in sicer z odhodom lastnih študentov na študij v tujino in z vzpostavljanjem programov, kampusov itn. tujih visokošolskih institucij na njihovem ozemlju ${ }^{10}$. To odpira precej vprašanj, povezanih s čezmejnim izobraževanjem, kot na primer, kako izboljšati izobraževalne zmogljivosti države gostiteljice na dolgi rok, kako prisotnost tujih institucij vpliva na poslabšanje položaja lokalnih visokošolskih zavodov itn., (International Association of Universities [IAU], 2012, str. 4). Vsekakor lahko pritrdimo, da »smo na razpotju današnji nastajajoči programi in prakse morajo zagotoviti, da internacionalno visoko šolstvo koristi javnosti in ni le profitno orientirano« (Altbach in Knight, 2007, str. 304).

\subsection{Beg možganov}

Mednarodna trgovina v visokem šolstvu je pospešila čezmejno izobraževanje, ki je s prenosom človeškega kapitala, znanja in informacij ključen dejavnik pri ustvarjanju družbe znanja, pa vendar je eno od večjih tveganj, ki jih lahko doprinese prav beg možganov (angl. brain drain). Odločitev o preselitvi v tujo državo temelji predvsem na razumevanju, da so plače in priložnosti drugje boljše od tistih v lastni državi. Ljudje pri tem različno vidijo svoje zaposlitvene možnosti, kar je odvisno tudi od njihove ravni izobrazbe. Pozitivna selekcija nastane, ko osebe z višjo stopnjo izobrazbe sprejmejo odločitev o selitvi zaradi višjih plač za visoko strokovno delo v tujini. Negativna selekcija izbire nastopi pri manj izobraženih osebah, ki se selijo zaradi višjih plač za nižje kvalificirana delovna mesta (Wheaton, Schaurer in Galli, 2010, str. 121). O begu možganov govorimo takrat, ko prihaja do gibanja zelo izobraženih posameznikov iz njihovih držav v druge države v pričakovanju boljših možnosti oziroma priložnosti. Velikokrat to pomeni prehod človeškega kapitala, temeljnega strateškega vira, ki prispeva k nacionalnemu blagostanju države, v tujo državo z dobro razvitim trgom delovne sile (Ramin, 1995 v Mugimu, 2010, str. 37).

\footnotetext{
10 Število odhajajočih študentov na študij v tujino se v večini držav v razvoju (od leta 1996 do 2008) skoraj dvakratno povečuje. V nekaterih primerih, kot je Bangladeš, je bilo povečanje trikratno in celo štirikratno $v$ primerjavi z Nigerijo. Malezija po drugi strani doživi upad odhajajočih študentov, vendar pojav delno povezujejo prav s prisotnostjo številnih podružnic tujih univerz in univerzitetnih kampusov, ki so začeli delovati na tem območju (Varghese, 2011, str. 16).
} 
Čezmejno izobraževanje vsekakor ni edini ključni dejavnik, ki vpliva na beg možganov, prispeva pa k vse večji migraciji akademskega, znanstvenega in strokovnega kapitala ter študentov. Pri tem se na eni strani spoprijemamo z begom že izobražene delovne sile, na drugi strani pa z mladimi, ki se izobražujejo v tujini. To pomeni težavo, ker precej študentov ostane v državi, kjer so dokončali študij. Avtorja Dreher in Poutvaara (2011, str. 1294), ki sta preučevala vlogo tujih študentov na primeru migracij v ZDA (ki je največja prejemnica mednarodnih študentov), sta ugotovila, da obstaja tesna povezava med tujimi študenti in migracijskimi tokovi. Letni študentski tok tako približno ustreza v povprečju za devet odstotkov letne migracije ob predvidevanju, da študentje navadno doštudirajo v štirih letih. Povečanje števila tujih študentov za 10 odstotkov vodi v povečanje priseljevanja med 0,3 in 0,94 odstotka (Dreher in Poutvaara, 2011, str. 1301). Vedno več univerzitetnih profesorjev in znanstvenikov se preseljuje v države, kjer so pridobili izobrazbo, kar povzroča slabitev akademskega kapitala v domačem okolju.

Beg možganov lahko pomeni resno tveganje $\mathrm{v}$ nekaterih delih sveta predvsem $\mathrm{z}$ izgubo človeškega kapitala, intelektualno abrazijo, demografskimi spremembami v državah, vplivom na trg dela in gospodarsko rast. Na splošno lahko različni migracijski fenomeni ob pomanjkanju informacij, ob nepredvidljivih dogodkih in napovedih predstavljajo izziv humanitarnim, ekonomskim, socialnim in kulturnim vidikom ter varnosti, obrambi in zunanji politiki države (Prezelj, 2007, str. 191). Kljub negativnim posledicam bega možganov se mobilnost študentov, akademskega osebja in znanstvenikov poskuša uporabiti za koristne povezave in vire pri širitvi visokošolskega izobraževanja, za izboljšanje kakovosti in mednarodnih povezav (IAU, 2012). Danes namreč veliko akademikov ohrani stike s svojo rodno državo ali visokošolsko institucijo prek informacijske tehnologije, sodelovanja pri raziskavah, z vračanjem v državo na posvete, na predavanja itn. (Altbach, 2005, str. 68). Države s svojo politiko in predvsem visokošolske institucije lahko takšne povezave zelo dobro izkoristijo in beg možganov premostijo v »dotok možganov«.

\subsection{Korupcija}

Kaj je korupcija? Kot pravi Begovic (2005, str. 1) »obstaja več odgovorov«. Korupcija ${ }^{11}$ je sicer univerzalen fenomen, vendar so njeni zaznavanje, dojemanje in tudi definiranje odvisni od različnih držav, organizacij, družbeno-političnega sistema, norm, vrednotnega sistema, stopnje integritete, kulture itn. Na svetu ni enotne definicije, med posameznimi državami in tudi institucijami so namreč precejšnje razlike v pojmovanju, iz česar izhajajo njene različne pojavne oblike ${ }^{12}$ (Dobovšek in Miklavćić, 2011).

\footnotetext{
${ }^{11}$ Korupcijo, ki danes predstavlja kompleksen in obširen problem v svetu, je ravno zaradi spreminjajoče in razvijajoče se oblike skozi zgodovino zelo težko definirati (Dobovšek in Miklavćić, 2011). Po zakonski opredelitvi $v$ RS je korupcija: »vsaka kršitev dolžnega ravnanja uradnih in odgovornih oseb v javnem ali zasebnem sektorju, kot tudi ravnanje oseb, ki so pobudniki kršitev ali oseb, ki se s kršitvijo lahko okoristijo, zaradi neposredno ali posredno obljubljene, ponujene ali dane oziroma zahtevane, sprejete ali pričakovane koristi zase ali za drugega" (Zakon o integriteti in preprečevanju korupcije, 2011).

12 Pojavne oblike korupcije so: podkupovanje, poneverba, kraja, goljufija, izsiljevanje, zloraba diskrecije, nepotizem, favoriziranje.
} 
$\mathrm{V}$ visokem šolstvu korupcija ni nov pojav in ni omejena le na države z manj uglednimi akademskimi sistemi ali na zasebne institucije niti samo na nacionalno raven. Njenih oblik ${ }^{13}$ je veliko, pojavljajo se v vseh segmentih visokošolskega delovanja in tudi od različnih deležnikov - študentov, zaposlenih in institucij. Nepreglednost pospešenega čezmejnega izobraževanja na globalnem trgu in vpletenost različnih akterjev na organizacijski, nacionalni in nadnacionalni ravni pa izraža pomembnost zavedanja o navzočnosti različnih novih pojavnih oblik in s tem povezanimi tveganji. Korupcija postaja vse bolj relevantna, saj z novimi oblikami čezmejnega izobraževanja nastajajo tudi nove priložnosti za koruptivna dejanja ${ }^{14}$, ki so danes povezana z zasebnimi univerzami, franšizami, akreditacijami, problemom agentov za novačenje tujih študentov, ponarejanjem listin itn., s čimer pridobiva tudi mednarodno dimenzijo ${ }^{15}$. Ob tem opozorimo na posebno obliko korupcije, za katero menimo, da postaja vse bolj pomembna - ujetost države oziroma ugrabitev države (angl. state capture). Besedna zveza pomeni »obseg, v katerem se podjetja poslužujejo dajanja nezakonitih in netransparentnih provizij državnim uslužbencem, z namenom vplivati na formuliranje zakonov, pravil, regulativ in odlokov, postavljenih s strani državnih institucij « (Dobovšek in Mastnak, 2012, str. 313). Njeno preučevanje je treba obravnavati tudi v kontekstu čezmejnega izobraževanja, saj sta obseg in oblika odvisna od zakonodaje držav izvoznic in prejemnic. Z omenjenimi koruptivnimi dejanji si lahko posamezni ponudniki pridobijo redke vire na globalnem trgu visokega šolstva.

Posledic je veliko, zlasti v povečanju neenakosti pri dostopu do visokošolskega izobraževanja, upočasnjevanje procesa kopičenja človeškega kapitala kot neposredni negativni učinki pri zaposlovanju, slaba usposobljenost diplomirancev, pozitivna percepcija korupcije študentov itn., (Dobovšek, 2009), kar se najbolj kaže pri uspešnosti in učinkovitosti gospodarskega razvoja in socialni koheziji ${ }^{16} \mathrm{v}$ državi, posledično tudi pri nacionalni varnosti (Osipian, 2007, 14). Poudariti bi želeli, da je obseg predvsem »novih« oblik korupcije, ki so povezane s čezmejnim izobraževanjem v svetu, še precej neraziskano področje, temeljni problem za preučevanje pa izhaja iz

\footnotetext{
13 Zasledimo jo v obliki vse od podkupovanja, poneverb, goljufij, nepotizma, klientelizma, pokroviteljstva, zlorabe osebnih poznanstev, favoriziranja, plačila podkupnine kot nagrade uradniku (angl. kickbacks), prepisovanja in prevare pri preverjanju znanja, plagiatov, kršitev pogodb, kršitev pri raziskavah, vedenjske, etične in spolne kršitve, zlorabe zasebne lastnine, pa vse do korupcije, povezane z izdajami in distribucijami učbenikov, slabega upravljanja in nepravilnega dodeljevanja javnih sredstev (Osipian, 2007, str. 315-316; Osipian, 2008, str. 350-351).

14 Altbach (2012) opozori na pred kratkim odmevne težave: a) škandal z zasebno neakreditirano »Tri-Valley univerzo« $v Z D A$, ki je s prevaro pobirala šolnine tujim študentom, b) agencije za zagotavljanje kakovosti $v$ Veliki Britaniji so odkrile nepravilnosti pri izvajanju »franšiznih « študijskih programov, s podobnimi problemi pa so se ukvarjali tudi v Avstraliji, c) na spletnem omrežju se pojavljajo »plačanci« za pisanje sprejemnih esejev/testov in ponujajo tudi druge vprašljive usluge, d) nekatere institucije privabljajo in zavajajo študente z akreditacijami, ki jih sploh ni itn.

${ }^{15}$ Zakon o integriteti in preprečevanju korupcije v svojem 4. členu določa, da je »mednarodna korupcija" korupcija, v kateri je udeležena najmanj ena fizična ali pravna oseba iz tujine (Zakon o integriteti in preprečevanju korupcije, 2011).

${ }^{16}$ Svet Evrope definira socialno kohezijo kot sposobnost družbe, da zagotovi blaginjo vsem njenim članom, zmanjšuje tveganja in odpravlja polarizacijo (Ministrstvo za delo, družino in socialne zadeve, 2013).
} 
različnega pojmovanja in definiranja korupcije posameznih držav ${ }^{17}$ in dejstva, da je korupcijo težko dokazati.

Begovič pravi (2005, str. 6-7), da korupcija povečuje poslovno negotovost, negotovost glede zaščite lastninskih pravic in kršenja načela pravne države, ki je predpogoj za tržno gospodarstvo. Z vsemi svojimi razsežnostmi dolgoročno škoduje nacionalnemu gospodarstvu, ga siromaši in tudi zavira družbeni razvoj. Posledice se »v najbolj splošnem smislu kažejo v obliki ekonomske neučinkovitosti in razsipništva ter preusmeritev proizvodnih in potrošnih tokov« (Dobovšek, 2012, str. 61-62). Korupcija, povezana s čezmejnim izobraževanjem (in predvsem v visokem šolstvu) lahko posredno vpliva na nacionalno varnost prek gospodarskega razvoja in zagotavljanja socialne kohezije v državi, ob upoštevanju, da nacionalna varnost v »vsebinskem smislu vključuje vse vidike človekovega obstoja in delovanja v družbi« (Grizold, 2005, 23). Kot je definirano v Resoluciji o strategiji nacionalne varnosti (2001), je »krepitev gospodarske stabilnosti in rasti pomembna tudi za razvoj varnostnih funkcij države. Dinamičen, trajnostni gospodarski razvoj in spodbujanje mednarodnega gospodarskega sodelovanja zmanjšujeta verjetnost napetosti, tveganj in konfliktov tako znotraj države, kot v mednarodnem prostoru«.

Sklep Varnost naroda, ki obsega tako zunanjo in notranjo varnost, država zagotavlja prek definiranja nacionalne varnosti, nacionalnovarnostne politike in nacionalnovarnostnih mehanizmov in sistemov. Ob tem se mora zavedati, da se $\gg v$ mednarodnem in nacionalnovarnostnem okolju 21. stoletja soočamo z raznovrstnimi sodobnimi viri ogrožanja in tveganja varnosti« (Resolucija o strategiji nacionalne varnosti, 2010).

Morda »pretirano« pozitivno dojemanje čezmejnega izobraževanja, hitro naraščanje dejavnosti in pomanjkanje podatkov o dejanskem stanju na svetovni ravni »vsiljujejo« razmislek o tveganjih. Relevantnost kritičnega pogleda na čezmejno delovanje visokega šolstva utemeljujemo predvsem z njegovo vlogo, ki sega vse od gospodarske rasti, izobraževanja, pridobivanja človeškega kapitala itn. do posledičnega vpliva h krepitvi nacionalne varnosti. S tveganji, na katera smo opozorili (neokolonializem, beg možganov in korupcija), vsekakor nismo zajeli vseh, omejili smo se na tista, ki so na podlagi preliminarnega pregleda literature najbolj pomembno vplivala na nacionalno varnost. Zavedamo se, da z omenjenim prispevkom nismo rešili vprašanj, niti predlagali mogočih ukrepov, temveč le podali kritični pregled v razmislek o trenutnem dogajanju. Tveganje namreč predstavlja verjetnost nevarnosti, za katero obstaja določena verjetnost, da se bo pripetila (Prezelj, 2002, str. 134), kar pomeni, da obstaja tudi možnost, da država in/ali visokošolski sistemi s preventivnim in strateškim delovanjem tveganja obvladujejo. Ugotavljamo, da sta za to nujno potrebni identifikacija in analiza stanja, ugotoviti je treba, kaj trendi pomenijo za prihodnost čezmejnega izobraževanja, kaj pomenijo z vidika ustvarjanja gospodarske konkurenčnosti in nacionalne varnosti. Prednosti omenjenega prispevka so

${ }_{17}$ Tako na primer $v$ »ZDA donacije niso obravnavane kot morebitne podkupnine v zameno za sprejem na prestižne univerze, preprosto zato, ker to predstavlja način, po katerem deluje njihov sistem «(Osipian, 2008, str. 351). 
predvsem v prikazu smiselnosti nadaljnjega raziskovanja pridobivanja podatkov o čezmejnem izobraževanju na nacionalni in svetovni ravni, nadaljnjem raziskovanju mogočih tveganj za posamezne države ter predvsem raziskovanja korupcije v visokem šolstvu.

1. Al-Rodhan, N., 2007. The role of education in global security. Geneva: Editions Slatkine.

2. Altbach, P. G., 2002. Knowledge and Education as international commodities. International higher education. 28-2, str. 2-5.

3. Altbach, P. G., 2005. Globalization and the university: Myths and realities in an unequal world. V National Education Assosiation, ur. The NEA 2005 almanac of higher education. Washington, DC: National Education Association, 2005, str. 63-74.

4. Altbach, P. G., 2012. Taking on corruption in international higher education, http://www. universityworldnews.com/article.php? story $=20120717134058780,15.7 .2013$

5. Altbach, P. G. in Knight, J., 2007. The Internationalization of Higher Education: Motivations and Realities. Education Journal of Studies in International. 11-3/4, str. 290-305.

6. Begovic, B., 2005. Corruption: concepts, types, causes and consequnces. Documentos. 3-26, str. 1-7.

7. Burgess, P. in Berquist, B., 2012. Cross-Border Delivery of Higher Education: Projects, Programs, and Providers. V D. K. Deardorff, H. De Wit, J. D. Heyl in T. Adams, ur. The SAGE Handbook of International Higher Education. Washington, DC: SAGE Publications, 2012, str. 325-342.

8. Centre for International Economics. 2008. APEC and international education, https:// www.aei.gov.au/research/publications/documents/apec and international education.pdf, 20. 6. 2012.

9. Chan, W. Y. 2004. International Cooperation in Higher Education: Theory and Practice. Journal of Studies in International Education. 8-32, str. 32-55.

10. Commission of the European Communities. 2003. Communication from the commission. The role of the universities in the Europe of knowledge, http://eur-lex.europa.eu/ LexUriServ/LexUriServ.do? uri=COM:2003:0058:FIN:en:pdf, 20. 6. 2012.

11. Dobovšek, B., 2009. Preprečevanje sodobnih korupcijskih pojavov v Sloveniji in izobraževanje. 20. Slovenski politološki dnevi (od 28. do 30. maja 2009). Portorož.

12. Dobovšek, B., 2012. Korupcija v tranziciji. Študijsko gradivo. Ljubljana: Fakulteta za varnostne vede.

13. Dobovšek, B. in Mastnak, M., 2012. Prevzem države-state capture. V B. Dobovšek, ur. Korupcija v tranziciji. Študijsko gradivo. Ljubljana: Fakulteta za varnostne vede, 2012, str. 300-496.

14. Dobovšek, B. in Miklavčič, K., 2011. Korupcija v politiki: razvojni pristop k preventivi. http://www.fvv.unimb.si/DV2010/zbornik/preprecevanje_korupcije/Miklavcic_Dobovsek. pdf, 13. 6. 2012.

15. Dobovšek, B. in Škrbec, J., 2012. Neformalne mreže. V. B. Dobovšek, ur. Korupcija v tranziciji. Študijsko gradivo. Ljubljana: Fakulteta za varnostne vede, 2012, str. 231-415.

16. Dreher, A. in Poutvaara, P., 2011. Foreign Students and Migration to the United States. World Development. 39-8, str. 1294-1307.

17. European Foundation for the Improvement of Living and Working Conditions, 2005. The knowledge society and Euphoria. http://www.eurofound.europa.eu/pubdocs/2004/14/en/1/ ef0414en.pdf, 15. 6. 2012

18. Grizold, A., 2005. Slovenija v spremenjenem varnostnem okolju k razvoju obrambnozašitnega sistema: izzivi in spodbude. Ljubljana: Fakulteta za družbene vede.

19. Grizold, A. in Bučar, B. (2011). Izzivi sodobne varnosti: od nacionalne in mednarodne do človekove varnosti. Teorija in praksa, 48(4), 827-851. 
20. Hough, P., 2004. Understanding Global Security. London: Routledge.

21. International Association of Universities, 2012. Affirming Academic Values in Internationalization of Higher Education. http://www.iau-aiu.net/sites/all/files/Affirming Academic_Values_in_Internationalization_of_Higher_Education.pdf, 14. 7. 2012.

22. Jiang, X., 2008. Towards the internationalisation of higher education from a critical perspective. Journal of Further and Higher Education. 32-4, str. 347-358.

23. Kehm, B. M. in Teichler, U., 2007. Research on Internationalisation in Higher Education. Journal of Studies in International Education. 11-7, str. 260-273.

24. Kelleher, A. in Klein, L., 1999. Global prespectives: a handbook for understanding global issues. New Jersy: Prentice Hall.

25. Knight, J., 2005. An Internationalization Model: Responding to New Realities and Challenges. VH. De Wit, I. C. Jaramillo, J. Gacel-ávila in J. Knight, ur. Higher education in latin america: the international dimension. Washington, DC: The world bank, 2005, str. $1-37$.

26. Knight, J., 2008. Higher education in turmoil: The changing world of internationalization. Canada: Sense publishers.

27. Knight, J., 2011. Higher education crossing borders: a framework and overview of new developments and issues. VR. Sakamoto in D. Chapman, ur. Cross-border partnership in higher education. Strategies and issues. London: Routledge, 2011, str. 16-41.

28. Kreber, C., 2009. Different perspectives on internationalization in higher education. New directions for teaching and learning. 118-9, str. 1-14.

29. Malešič, M. (1994). Teoretične perspektive sodobne varnosti. Javnost, 1(4), 97-104.

30. Marginson, S., 2004. Competition and Markets in Higher Education: a 'glonacal' analysis. Policy Futures in Education. 2-2, str. 175-244.

31. Ministrstvo za delo, družino in socialne zadeve. 2013. http://www.mddsz.gov.si/si/ delovna_podrocjalenake_moznosti_in_evropska_koordinacija/zakonodaja_in_dokumenti mednarodne_organizacije/coe/sociälna_kohezijä, 10. 1. 2013.

32. Mugimu, C. B., 2010. Brain Drain to Brain Gain: What are the Implications for Higher Education in Africa? Comparative \& International Higher Education. 2-10, str. 37-42.

33. Nkrumah, K., 1965. Neo-Colonialism, the Last Stage of imperialism. http:// politicalanthro.files.wordpress.com/2010/08/nkrumah.pdf, 20. 7. 2012.

34. Nokkala, T., 2006. Knowledge society discourse in internationalisation of higher education. Case study in governmentality. Revista Española de Educación Comparada. 12-6, str. 171-201.

35. Obramboslovni raziskovalni center. 2003. Nacionalna in mednarodna varnost 2003. http://nato.gov.si/slo/javno-mnenje/nacionalna-varnost.pdf, 12. 7. 2012.

36. Osipian, A. L., 2007. Corruption in Higher Education:conceptual approaches and measurement techniques. Research in Comparative and International Education. 2-4, str. 313-332.

37. Osipian, A. L., 2008. Corruption in higher education: does it differ across the nations and way? Research in comparative and international education. 3-4, str. 345-365.

38. Prezelj, I., 2002. Grožnje varnosti, varnostna tveganja in izzivi v sodobni družbi. Razrě̌evanje nekaterih terminoloških dilem. Teorija in praksa. 38-1, str. 127-141.

39. Prezelj, I., 2007. Model celovitega ocenjevanja ogrožanja nacionalne varnosti Republike Slovenije. Ljubljana: Ministrstvo za obrambo, Direktorat za obrambne zadeve, Sektor za civilno obrambo.

40. Resolucija o strategiji nacionalne varnosti Republike Slovenije (ReSNV-1), 2010. Uradni list $R S$ št. 27/2010.

41. Resolucija o strategiji nacionalne varnosti Republike Slovenije (ReSNV), 2001. Uradni list RS št. 56/2001. 
42. Sotlar, A., 2001. O oblikovanju nacionalnovarnostne politike-identifikacija ključnih formalnih in neformalnih akterjev in dejavnikov. Varstvoslovje. 3-3, str. 190-201.

43. Svete, U., 2005. Varnost v informacijski družbi. Ljubljana: Fakulteta za družbene vede.

44. Teichler, U., 2009. Internationalisation of Higher Education: European Experiences. Asia pacific education review. 10-1, str. 93-106.

45. Tilak, J. G., 2011. Trade in higher education: The role of the General Agreement on Trade in Services (GATS). Paris: UNESCO.

46. Valimaa, J. in Hoffman, D., 2008. Knowledge society discourse and higher education. High Education. 56-8, str. 265-285.

47. Varghese, N. V., 2011. Globalization andcross-border education: Challenges for the development of higher education in Commonwealth countries. http://unesdoc.unesco.org/ images/0019/001915/191584e.pdf, 12. 7. 2012.

48. Wheaton, E. M, Schaurer, E. J. in Galli T. V., 2010. Economics of human trafficking. International migration. 48-4, str. 115-141.

49. Zakon o integriteti in preprečevanju korupcije uradno prečiščeno besedilo. 2011. Uradni list RS št. 69/2011. 